\title{
Modeling Credit Risk in Banking
}

\author{
Katerina Larionova \\ Department of Finance, Banking and \\ Insurance \\ Khmelnytskyi National University \\ Khmelnytskyi, Ukraine \\ k_larionova@i.ua \\ Hennadii Kapinos \\ Department of Economics, \\ Management and Administration \\ Khmelnytskyi National University \\ Khmelnytskyi, Ukraine \\ p_kapinos@i.ua
}

\author{
Tetyana Donchenko \\ Department of Finance, Banking and \\ Insurance \\ Khmelnytskyi National University \\ Khmelnytskyi, Ukraine \\ donchtv@gmail.com
}

\author{
Andriy Oliinyk \\ Department of Finance, Banking and \\ Insurance \\ Khmelnytskyi National University \\ Khmelnytskyi, Ukraine \\ oleynik_andrey@hotmail.com
}

\begin{abstract}
The appropriate credit risk assessment the use of risk management methods are essential for bank financial firmness and stability as well as determinative for the behavioral aspects of bank operation. The article develops a model of credit risk assessment within the scope of the variability concept that can be used for verification of new methods for borrowers' credit capacity estimation, the acceptable level of credit risk forecasting and its early prediction. It is aimed to be used in the process of the automated banking systems designing. The proposed model allows to apply a comprehensive credit risk assessment using means of probability theory, integral calculations and differential equations, which enable to predict the credit risk level and make effective management decisions. In accordance with the concept of variability, the model may be applied in behavioral banking. The article highlights some advantages and limitations of the model application. The proposed model of credit risk assessment has been tested on the basis of the data from one of the Ukrainian banks. The adequacy of this model has been proved by the comparison analysis of the proposed model with the results obtained by the National Bank of Ukraine methodology.
\end{abstract}

Keywords—credit risk, credit portfolio, risk management

\section{INTRODUCTION}

The questions of effective strategic and tactical bank management are directly associated with the credit risk, which should be acceptable. Taking into account the fact that it is not possible to avoid credit risk completely, the problem of its estimation is of great relevance, since its accuracy affects the minimization of this risk and the choice of the most effective strategy of its management. The appropriate credit risk estimation and the use of risk management methods can be a guarantee of bank financial firmness.

Taking into account the economic literature and practice, it can be concluded that the concept of risk is quite multifaceted and can have different meanings depending on the specific scenarios. However, risk is broadly defined as the uncertainty of a particular event occurrence in future. In the banking business the risk refers to financial losses that may take place during the certain transactions performance. In terms of mathematics the risk can be measured by the probability that an anticipated event will not happen and it will lead to negative consequences or losses. It should be emphasized that banking business is rather specific, as it is characterized by high riskiness on the one hand, and assurance of reliability and trust, which are realized through providing certain guarantees to clients - on the other hand. The banking system of Ukraine as well as the world banking practice often faces the problem associated with estimation of credit risk, which can lead to financial losses in the result of default on borrower's commitments. According to the requirements of Basel Committee banks by their own should choose methodologies to estimate and model credit risk in their business [1]. Therefore, the problem of choosing modeling methods for credit risk assessment in banking business is of great relevance and controversy. It is obvious that banks have to create and implement their own risk management systems in order to achieve success in high-risk lending activities. It is these systems which help the management apparatus to identify, estimate and control corresponding risks. The decision-making system should not only identify and assess the credit risk, but also determine its justifiability or tolerability in terms of the profitability of lending transaction. Acceptable risk is also possible, since it does not threaten the bank, and the eventual losses are less than expected profit and the amount of the compensation for possible losses reserve, which is specially created for the given transaction. Each banking institution defines the limits of acceptable risk by its own according to the chosen management strategy. However, the risk that exceeds the permissible limits is critical, that means that it is much higher than the amount of expected profits and the reserve created. The upper limit of the critical risk is determined by the bank's fund value, so in case of risk event the bank will not make a profit, as well as will lose its own fund. If the risk magnitude is even higher than the critical risk, the bank goes into bankruptcy which is succeeded by the liquidation procedure and the assets sale.

Credit risk is an important component of any bank portfolio and needs to be controlled and managed regularly. It is necessary to use the modern modeling methods and information technologies in order to reduce credit risk and determine its main indicators (probability of default, credit risk appetite, etc.).

The first who began to develop the credit risk assessment econometric models were Altman (Z-score model), Beaver 
and Tamar. Since then, the models have been improved by scientists and become more elaborate. Domestic and foreign scholars [2-5] in their papers on credit risk assessment develop and refine models, which help to determine according to the research purpose the probability of default, the level of loan portfolio losses, the variation amount of the loan portfolio value, the probability of non-redemption of nonperforming loans and others.

In recent years, large foreign financial institutions have developed a range of credit risk assessment models that vary in elaboration and application methodologies and are widely recognized throughout the world. CreditRisk+, CreditMetrics, Moody's KMV Portfolio Manager, Credit Monitor i CreditPortfolioView models are among them. They allow to determine with different accuracy level the amount of losses associated with credit risk and to calculate the loan derivative value at risk (value at risk). The models mentioned above have their own peculiarities, but their purpose is the same - to determine the losses apportionment in the credit risks portfolio and, on this basis, to calculate the expected loss in the portfolio at any confidence interval, the change in the extent of these losses and the amount of funds needed for the portfolio support. In recent years, SVM model developed by Bernhard E. Boser, Isabelle M. Guyon, and Vladimir N. Vapnik [6] has become more and more popular in the framework of the defaults forecasting as a nonlinear nonparametric algorithm for classification. Western commercial banks and rating agencies implement it in their business (McKinsey; Adrian Costeiu, Florian Negu). However, despite its obvious advantages, SVM model has some limitations in loan scoring practice.

The review of existing techniques is extremely important for selection, implementation and adaption of the most appropriate model. At the same time, selecting the most appropriate approach, it is necessary to take into account the available mathematical tools, the nature and the quality of benchmark data, the planning horizon, the study objectives and the specifics of the bank portfolio. The personnel skill level, the extent of adoption and usage the latest IT systems and products in the bank are also of great importance. The usage of foreign models is rather complicated, as they have to be adjusted to the Ukrainian economy realities or the own models for credit risk assessment should be developed. The proposed model allows to apply a complex credit risk assessment using the probability theory apparatus, integral calculations and differential equations, which enables to predict the credit risk level and make effective managerial decisions in risk management.

\section{METHOD}

A number of situations in which credit risk has been demonstrated have been investigated in the scope of the relevant study and mathematical models based on probability theory have been developed. In this case, the risk measurement procedure involves constructing of $\rho$ function, which assigns a number to each random allocation:

$$
\rho: Y \rightarrow R
$$

where $Y$ is the set of permissible in the particular problem probable distributions that represent risks; $R$ is the set of real numbers.
The analysis and systematization of scientific sources and practical experience, at the present stage, distinguishes the next concepts in the structure of financial risks measurement procedures [7], [8]: losses in adversity; variability; financial risks measurement in the framework of within the expected utility theory; sensitivity.

The risks measurement according to the concept of losses in adversity is a relatively widespread phenomenon in world practice and the domestic banking system. Thus, it is proposed to estimate the expected losses assessed by the bank, depending on the probability of the borrower default, the amount of default losses and the loan extent at the time of default in order to assess credit risk under Basel II [1]

$$
E L=P D \times L G D \times E A D
$$

where $E L$ - expected losses; $P D$ (probability of default) the probability that the borrower will not be able to fulfill his obligations under the contract; $L G D$ (loss given default) - the percentage of losses as relating to the credit amount that the bank will take at the time of the borrower default; EAD (exposure at default) - the loan amount granted at the moment of default.

Under this approach based on the Internal Rating (IRB) the bank will only assess the probability of default and will use data on losses in case of default and exposure to default provided by a credit or rating agency. The European Union has also adopted this methodology by the Capital Adequacy Directive [9]. The National Bank of Ukraine (NBU) recommends this method to commercial banks for effective market risk management.

It is necessary in the framework of this paper to consider more precisely the concept of variability. It is based on the identification of so-called "location indicators", relating to which variability is calculated. As a rule mathematical expectation, variance, median, mode, quantile can be used as "location indicators". In the scope of the variability concept loan risk has been constructed, as it is the most widespread and elaborate in the banking activity. Formalized approach to the credit financing has helped to come to conclusion that the lending process, especially at the stage of chargeback and repayment of deposit percentage, can be considered as a functional relationship to the time that is random variable. Therefore, it is reasonable to consider this process as a flow of borrower's payments at the certain point of time with a corresponding probability. Formalized approach to the credit operations also has allowed us to conclude that credit risk can be observed in three aspects. Firstly, the borrowers do not reimburse the bank loans entirely. Secondly, borrowers do not reimburse bank loans on schedule. Thirdly, borrowers reimburse bank loans entirely, but not on time and by partial amounts at one's own wish, breaking the loan amortization schedule both in time and amount payments. In practice, as a rule, all three aspects of credit risk can be observed simultaneously. Simultaneous action of all the aspects of credit risk will not be considered, as the situations when the loan is not reimbursed by the borrower and the payments are delayed in time are helpful in the analysis of the credit risk elementary components. It is supposed that the symbiosis of these components will help to simulate the third aspect of the credit risk. It can be argued that the process represents a functional relationship to time, as in case of incomplete 
credit repayment time latency will be observed. On the one hand, if the borrowers do not reimburse the entire amount of the credit, constructing a model it is necessary to take into account the reduction of the amounts which are returned according to maturity dates on schedule, and, on the other hand, in the case of the complete loan amortization, which is repaid with maturity dates break, it is necessary to consider the payments delay time when the repayment amounts are reimbursed completely.

It is obvious that, in its simplest form, the credit reimbursement process can be considered as a repayment of the credit sum $S$ at the moment of time $\tau$. Taking into account the fact that the credit reimbursement process is continuous in time, can change over time, and moreover, it can be of random character in terms of the sums of loan repayments, it is reasonable to introduce a function of time $\xi(t)$, which determines the loan repayment amount at time $t$. Thus, the appearance of a payment at time $t$, referring to the loan reimbursement, is a random variable and the value of the function $\xi(t)$ will be directly proportional to the loan repayment amount at time $t$. If the function $\xi(t)$ indicates by the flow of loan repayment amounts, each succeeding payment may lead to full or partial loan repayment. Therefore, it is reasonable to use the Boolean function $F(U)$ to define the flag indicator $U$ according to which the loan is reimbursed completely. Correspondingly, if $F(U)=1, U$ possess the "truth" value, that means, that credit has been reimbursed completely, and if $F(U)=0, U$ possesses "false" value, that means, that the loan has not yet been repaid.

First of all, it is necessary to consider the situation of incomplete loan reimbursement. Since the process is of random nature, let's define the random variable $\mu$, which denotes the proportion of the reimbursed loan and, correspondingly, takes the value on the interval $[0,1]$. Thus, the incomplete loan reimbursement process can be represented by the next formula:

$$
\xi(t)=\mu \times S \times F\{t \geq \tau\}
$$

where $\mu$ is a random variable; $S$ is a loan repayment amount before reimbursement process; $F\{t \geq \tau\}$ is a Boolean function.

It is obvious that the random variable $\mu$ has a probabilistic nature and the parameters of its distribution form the variable which characterizes the risk of lending operations. Correspondingly, if the probability $P\{\mu=1\}=1$, there is no risk, and if $P\{\mu=0\}=0$, there is the risk event. The nature of this distribution is rather interesting, problematic and highly discussed among the scientists. In the scope of this paper the distribution of random variable will be considered to be normal. In general, the parameters of this distribution can be investigated: on the basis of the mathematical expectation $(E)$ of a random variable:

$$
\begin{gathered}
E_{\xi(\tau)}=S \times E_{\mu} \\
D_{\xi(\tau)}=S^{2} \times D_{\mu}
\end{gathered}
$$

In this case the payment at the time $t$ is a random variable, correspondingly, $E_{\xi(\tau)}$ and $D_{\xi(\tau)}$ are the average and the variance of the payments flow, $S \cdot E_{\mu}$ is the loan repayment average amount. Let's consider the next case, when loans are returned, but not on schedule, and there is the certain delay time relating to the loan amortization schedule, which can be defined by $\delta$. Thus, the loan reimbursement process can be represented by the formula:

$$
\xi(t)=S \times F\{t \geq \tau+\delta\}
$$

It is obvious, that $\delta$ is random variable, which cannot be of negative value and the parameters of its distribution characterize the risk of credit operations. Thus, there is no risk in the case of $P\{\delta=0\}=1$, and the risk is very high in the case of $P\{\delta=\infty\}=0$, that means that the loan is not reimbursed. Simulating this process, it has been assumed that as the final result the loan would be reimbursed. The amount of payments at any moment of time $t \geq \tau$ can possess the values 0 or $S$. Regarding the payments flow, the loan repayment amount 0 or $S$ can appear at different moment of times $t$ with varying probability. Thus, the flow average value and variance will be correspondingly equal to:

$$
\begin{gathered}
E_{\xi(t)}=S \times P\{\delta \leq t+\tau\} \\
D_{\xi(\tau)}=S^{2} \times P\{\delta \leq t-\tau\} \times(1-P\{\delta \leq t-\tau\})
\end{gathered}
$$

In this model, the average delay time is $\delta$, and the average loan repayment amount is $S$, that means, that the model presumes that sooner or later the loan will be reimbursed. Further the model which would try to take into account all the aspects of credit risk, such as time delays and loan reimbursement payments has been built. The set of random variables possessing values on the interval $[0,1]$ has been defined as $\left\{\mu_{t}, t \geq 0\right\}$ and the following equation is true for it:

$$
P\left\{\mu_{0}>z\right\}>0 \text { to all } \mathrm{z}<1
$$

Thus, it is possible to estimate the effect of all the credit risk aspects with the help of the next correspondence:

$$
\xi(t)=\mu_{t-\tau} \times S \times F\{t \geq \tau\}
$$

In this case, the possibility of loan reimbursement by repeated partial payments is taken into account. In addition, the equation (9) ensures a positive probability of complete loan reimbursement on schedule, since it is not rational to assume that the loan has been issued if there has been the confidence that the borrower would not able to return it. Thus, the next model is built:

$$
\begin{gathered}
E_{\xi(t)}=S \times E_{\mu_{t-\tau}} \\
D_{\xi(t)}=S^{2} \times D_{\mu_{t-\tau}}
\end{gathered}
$$

Correspondingly, the average return share is equal to: 


$$
\lim _{t \rightarrow \infty} E_{\mu_{t}}
$$

Practical calculations for this model face the problem of determining the start values, for example, the probabilistic distribution of the loan repayment random variable $\mu$. We believe that the normal (Gaussian) distribution of a random variable is appropriate for this, however $\mu$ should have a positive value and cannot greater than 1 , as this will contradict the normal distribution condition. If, however, the given random variable is assumed to be Gaussian with some restrictions, and to characterize the amount of client's available assets with the help of which the loan can be reimbursed, its values which exceed mean, that a client has spare funds and the loan can be completely repaid, and if this random variable is of negative value, a client is insolvent or debtor.

Let's estimate the parameters of these models, since only if these parameters exist the model can be implemented in practice. For example, let's consider the first model and set the distribution of the partial loan repayment random variable $\mu$. It is necessary to choose a set of distributions to which $\mu$ can be attributed for this purpose. The normal (Gaussian) distribution, which is defined by the mathematical expectation $E$ and the variance $D$ has been chosen. However, the usage of normal distribution is still controversial. Firstly, $\mu$ must be of positive value. Although it is not of great importance, since taking into account the typical values of $\mu$ makes the probability of its negative value so slight that it can be neglected. Secondly, the $\mu$ partial cannot be greater than 1 , and such a probability for a normal distribution with typical values of $E$ and $D$ is very high. So, how this problem can be solved?

It can be assumed that there is a random Gaussian variable $\lambda$ that characterizes the borrower's ability to repay the loan in order to solve this problem. Let's suppose, for example, that it is the indicator of borrower's available assets at the time of debt repayment. Thus, if $\lambda$ is greater than 1 , a borrower has even more funds than needed for complete loan reimbursement and a bank can receive its assets on schedule. If $\lambda$ is less than 1 , a borrower not only does not have enough money to repay the current loan, but probably has other debts. Thus, the next equity can be truth for any random variable $\lambda$, which characterizes the client's ability to reimburse the credit:

$$
\mu=\min (\max (\lambda, 0), 1)
$$

Further it is necessary to define the parameters $E$ and $D$. It is sufficient to estimate the mathematical expectation of $E_{\mu}$ and the probability $P\{\mu=0\}$ in order to do this. The usage of the bank balance data, that are turnover and balance data on the corresponding accounts, is the easiest way to do this. It is obvious that this estimation can be obtained by dividing the total amount of delayed loan payments by the total loan amount.

Let's denote the repayment amount of loan debt obligations, the obtaining of which is scheduled at the moment of time $t$ by $P(t)$, and let's indicate the amount of delayed payments, which maturity date at the time $t$ has already passed, by $B(t)$. Thus, the loan reimbursement process can be characterized by the functions $p(u)$, where $P(t)$ is the volume from the repayments amount received by the bank for the time increment $u$ (from time $t$ to time $t+u$ ), and $b(u)$ is the proportion from the repayments amount $P(t)$, which has not been paid at time $t$. It is obvious, that:

$$
\begin{aligned}
& p(0)=b(0)=0 \\
& p(u)+b(u)=1
\end{aligned}
$$

As it can be seen, these functions do not vary depending on time $t$ and therefore, it is appropriate instead of $P(t)$ and $B(t)$ to take their mean values $P$ and $B$ for the time interval $u$. Thus, the $E_{\mu}$ can be estimated by the approximate formula:

$$
E_{\mu}=B / P
$$

where $B$ is the mean value of the delayed payments amount; $P$ is the mean value of the repayment amount of the debt obligations on the loan.

Formula (17) does not vary depending on the scale of the time measurement and, therefore, is correct, and the $B$ and $P$ variables are defined by the balance sheet. It is obvious, that this is not the only way to estimate $E_{\mu}$, and, therefore, the question can be controversial. It should be noted that in this case the model parameters has been estimated in simplified way and therefore the initial results of the research can be extended in the direction of detalization, justification and elaboration. Let's try to define the result obtained above more exactly. Let's define the amount of bad debts that have been written off at the cost of the reserve at time $t$ and are nonreturnable - by $Z(t)$ is. Thus, the loan reimbursement process can be characterized by the functions $p(u)$, where $P(t)$ is the volume from the repayments amount received by the bank for the time increment $u$ (from time $t$ to time $t+u$ ), $b(u)$ is the proportion from the repayments amount $P(t)$, which has not been paid at time $t$, and $z(u)$ is proportion of the payments amount $P(t)$ that has been written off. It is obvious, that:

$$
\begin{gathered}
p_{t}(0)=b_{t}(0)=z_{t}(0) \\
p_{t}(u)+b_{t}(u)+z_{t}(u)=1
\end{gathered}
$$

If it is assumed that the nature of requirements for debt forgiveness does not depend on the time, they are scheduled for, that means, that the requirements quality are approximately the same, these functions do not vary depending on time $t$. Thus, the next estimation for the functions $B(t)$ and $Z(t)$ can be obtained:

$$
\begin{aligned}
& B(t)=\int_{0}^{\infty} P(t-u) \cdot g^{\prime}(u) d u \\
& Z(t)=\int_{0}^{\infty} P(t-u) \times z^{\prime}(u) d u
\end{aligned}
$$


The process of loan payments obtaining and writing off in the general case can be represented by a system of differential equations:

$$
\begin{aligned}
& p^{\prime}(u)=\alpha \times b(u) \\
& z^{\prime}(u)=\beta \times b(u)
\end{aligned}
$$

Thus, taking into account the formulas (9) and (10), the system of equations has been developed:

$$
\left\{\begin{array}{l}
p^{\prime}(u)=\alpha \times b(u) \\
z^{\prime}(u)=\beta \times b(u) \\
p_{t}(0)=b_{t}(0)=z_{t}(0) \\
p_{t}(u)+b_{t}(u)+z_{t}(u)=1
\end{array}\right.
$$

Let the average values of $P(t), B(t), Z(t)$ to be correspondingly $P, B, Z$ for a certain period of time. Thus, after substituting the mean values in formulas (20), (21) and finding the solution of the obtained system of differential equations, the following approximate formula for $E_{\mu}$ estimation can be developed:

$$
E_{\mu}=\frac{1-\frac{Z}{P}}{1+\frac{B}{P}}
$$

where $B$ is the mean value of the delayed payments amount; $P$ is the mean value of the repayments amount of the loan debt obligations; $Z$ is the mean value of the bad debts amount that have been written off at the cost of reserves.

Moreover, investor's ration can be added to the model. Thus, overelaborating of the model gives the possibility to make more extended analysis of the information on bank credit risks elimination:

$$
E_{\mu}=\frac{1-\frac{Z}{P}}{1+\frac{r \times B}{P}}=\frac{P-Z}{P+r \times B}
$$

where $r$ is the coefficient that can be defined as a market category, such as market risk.

At the last stage the level of credit risk is determined by $E_{\mu}$ variable interpretation with the help of linguistic characteristics of the bank credit risk levels scale (Table 1). The proposed scale is based on the calculation of the integrated index of the financial status of a debtor - a corporate entity class, applying the correction factors specified in paragraph 22 Section II of the NBU Regulation №351. Loan payment by a debtor - a corporate entity in time is adopted as correction factors. However, the following demands should be hold to: if there is a delayed payment from 31 to 60 days - the bank gives a debtor the class that is not higher than 5; if this payment is delayed from 61 to 90 days, the class is not higher than 8 ; in the case of 91 and more days of delayed payment, a debtor gets the class not higher than 10 [10]. Taking into account the fact that the NBU methodology can define the credit risk losses volume, and the proposed model can determine the loan repayment level, it can be concluded, that estimation scales are of inverse character.

Thus, in our opinion, it is necessary to distinguish the following levels of credit risk: acceptable, moderate and critical.

TABLE I. CHARACTERISTICS OF BANK CREDIT RISK LEVELS

\begin{tabular}{|c|c|l|}
\hline $\begin{array}{c}\text { Credit } \\
\text { risk level }\end{array}$ & $\begin{array}{c}\text { Credit risk } \\
\text { bounds }\end{array}$ & \multicolumn{1}{c|}{ Characteristics } \\
\hline Acceptable & $1.00-0.90$ & $\begin{array}{l}\text { Risk of low level, which can be temporarily } \\
\text { ignored. Acceptable payment delay - from 31to } \\
60 \text { days }\end{array}$ \\
\hline Moderate & $0.89-0.41$ & $\begin{array}{l}\text { Moderate risk level, which should be carefully } \\
\text { controlled by bank management. Acceptable } \\
\text { payment delay - from 61 to 90 days }\end{array}$ \\
\hline Critical & $0.40-0$ & $\begin{array}{l}\text { Risk of high level, which can lead to bankruptcy. } \\
\text { Acceptable payment delay - from 91 days }\end{array}$ \\
\hline
\end{tabular}

The mathematical expectation of the credit risk level $E_{\mu}$ acquires a value in the range $\{0 ; 1\}$, and the closer it is to 1 , the lower the bank credit risk level is. Thus, the formula for $E_{\mu}$ estimation has been developed. It does not depend on time and uses data that can be obtained from the bank's balance. It is obvious that the result obtained is not the only solution to this problem and can be clarified by different ways, which need to be discussed in further investigations.

It should be noted that the proposed model has certain advantages and limitations. The main advantages are: an integrated approach to the credit risk assessment modeling, which involves various loan repayment scenarios that are relevant from the aspect of early diagnosis of possible credit risk and the bank's decision of its minimization or taking. Taking into account the high share of problem loans in domestic banks, this advantage is particularly important; the possibility to use this model to predict the acceptable level of credit risk, on the basis of which the optimal credit portfolio can be formed; flexibility in application of this model, as it can be used both for the credit risk assessment of the bank credit portfolio in general, and for its components (for example, for a credit portfolio of corporate clients or individuals); ease of use and implementation of this model in bank information systems. The main difficulties associated with the integrated credit risk assessment based on the proposed model are: insufficiency or total absence of historical data; the absence or inconsistency of statistical data due to the specifics of the banking business or the credit policy peculiarities. However, this should not prevent the banks from developing and applying the proposed model, the input data for which can be obtained from the open source information or based on the experts' reports. The development and implementation of the own methods and models for credit risk assessment, which will provide risk management with the input data for the formation of a bank credit strategy is an extremely important step for domestic banks. In general, it can be argued that there is a problem of effective modeling of credit risk according to the variability concept. This is primarily associated with the asymmetry of the lending activities process, which results into an 
asymmetric distribution of random variables and correspondingly increases the margin of error, as in the case of the Gaussian distribution. On the other hand, indicators in this model have a tendency to "dispersion" or "scattering" in different directions, that is not inherent in the risk assessment, since as a rule, deviation is considered under adversity. Despite the fact that there are problems referring model parameters assessment, they have been estimated with some restrictions and can be specified in other ways. As a result the obtained formulas using the real balance data of the balance can be implemented in the banking systems development.

\section{RESULTS AND DISCUSSION}

Let's consider the proposed credit risk assessment model on the example of the Ukrainian JSC CB PrivatBank. The obtained results will be compared with the results obtained by the method proposed by NBU in order to determine the model adequacy. The calculation of the mathematical expectation of loan repayments according to the proposed model and the analysis of the results are represented. Taking into account these resultsr, it can be concluded that the $E_{\mu}$ value is the most closely approximate to zero, that gives evidence of the critical level of JSC CB PrivatBank credit risk in 2018, which corresponds to the results of the NBU methodology. The results obtained with the help of the proposed model and the NBU methodology do not differ significantly by the majority of indicators. Thus, it can be concluded that the proposed model is an effective tool for credit risk assessment in banking business. This statement has been tested on actual data.

TABLE II. COMPARATIVE RESULTS OF THE JSC CB PRIVATBANK CREDIT RISK ASSESSMENT ACCORDING TO THE PROPOSED MODEL AND THE NBU METHODOLOGY

\begin{tabular}{|c|c|c|c|c|c|c|c|c|}
\hline \multirow[b]{2}{*}{ Date } & \multicolumn{6}{|c|}{ According to the proposed model } & \multicolumn{2}{|c|}{ According to the NBU methodology [14] } \\
\hline & $\begin{array}{c}B \\
\text { (UAH } \\
\text { billion) }\end{array}$ & $\begin{array}{c}Z \\
\text { (UAH } \\
\text { billion) }\end{array}$ & $\begin{array}{c}P \\
\text { (UAH } \\
\text { billion) }\end{array}$ & $E_{\mu}$ & $\begin{array}{c}\text { Repay-ments } \\
\text { amount } \\
\text { (UAH billion) }\end{array}$ & $\begin{array}{c}\text { Losses volume } \\
\text { (UAH billion) }\end{array}$ & $\begin{array}{l}\text { Losses according to the } \\
\text { compromise scenario, } \\
\text { (UAH billion) }\end{array}$ & $\begin{array}{c}\text { Losses according to the } \\
\text { aggressive scenario } \\
\text { (UAH billion) }\end{array}$ \\
\hline 01.02 .18 & 2.936 & 209.849 & 212.785 & 0.0136 & 2.894 & 209.891 & 209.942 & 210.189 \\
\hline 01.03 .18 & 3.216 & 208.903 & 212.119 & 0.0149 & 3.161 & 208.958 & 175.456 & 175.565 \\
\hline 01.04 .18 & 3.557 & 203.033 & 206.59 & 0.0169 & 3.491 & 203.099 & 203.124 & 203.412 \\
\hline 01.05 .18 & 3.991 & 203.064 & 207.055 & 0.0189 & 3.913 & 203.142 & 203.141 & 203.479 \\
\hline 01.06 .18 & 4.435 & 202.817 & 207.252 & 0.0209 & 4.332 & 202.920 & 202.975 & 203.334 \\
\hline 01.07 .18 & 4.936 & 203.253 & 208.189 & 0.0231 & 4.809 & 203.380 & 203.836 & 204.247 \\
\hline 01.08 .18 & 4.971 & 204.588 & 209.559 & 0.0232 & 4.862 & 204.697 & 204.694 & 205.427 \\
\hline 01.09 .18 & 5.314 & 206.986 & 212.3 & 0.0243 & 5.159 & 207.141 & 207.105 & 207.455 \\
\hline 01.10 .18 & 5.810 & 215.182 & 220.992 & 0.0256 & 5.657 & 215.335 & 215.43 & 215.769 \\
\hline 01.11 .18 & 6.194 & 215.488 & 221.682 & 0.0272 & 6.030 & 215.652 & 215.807 & 216.235 \\
\hline
\end{tabular}

\section{CONCLUSION}

The proposed model of credit risk assessment according to the concept of variability is universal and allows us to predict the credit risk level and make effective management decisions due to the means of probability theory, integral calculations and differential equations. This model provides to determine the mathematical expectation using data, which are not dependent on time and can be obtained from a banking institution's balance sheet. The model uses a comprehensive approach to credit risk assessment modeling, which involves different ways of loan repayment. The proposed model for credit risk assessment is one of a set of models, which is primarily can be used during development of automated banking systems, credit risk management systems and expert systems. This model can be also useful for verification of new methods for borrowers' credit capacity assessment and credit risk forecasting. The model can be included to the so-called "block of models", which is a part of modern decision-making systems. They can be used in banking business, that significantly increases the level of financial management in the area of credit risk management.

\section{REFERENCES}

[1] Basel Committee on Banking Supervision (BCBS) (2005, July), Basel II: International Convergence of Capital Measurement and Capital Standards: A revised framework, comprehensive version. [Online]. Available: http://www.bis.org/publ/bcbsc111.htm.
[2] Ruoyu Cai, Mao Zhang, "How does credit risk influenceliquidity risk? Evidence from Ukrainian banks", Visnyk of the National Bank of Ukraine, no. 241, pp. 21-33, 2017.

[3] Somnath Chatterjee, Modelling credit risk. London, 2015. [Online]. Available: https://www.bankofengland.co.uk/-/media/boe/files/ccbs/ resources/ modelling-credit-risk. Accessed on: July 19, 2019

[4] O. A. Gostrik, O. A. Stepanenko, "Definition of permissible credit risk of commercial bank with using the method of system dinamics", Scientific Herald of Uzhgorod National University, vol.6, no. 3, pp. 60-63, 2016.

[5] Her-Jiun Sheu, Chih-Liang Liu, "The Credit Risk Pricing with Particle Filter Approach", in Proc. 9th Joint International Conference on Information Sciences (JCIS-06), 2006.

[6] B. E. Boser, I. M. Guyon, and V. N. Vapnik, "A Training Algorithm for Optimal Margin Classifiers", in Proc. 5th Annu. ACM Workshop on Computational Learning Theory, Pittsburgh, 1992, pp.144-152.

[7] V.V. Vitlinskyi, and H. I. Velykoivanenko," Financial risk and methods of its measurement", Finance of Ukraine, vol.12. pp. 13-23, 2000 .

[8] A.B. Kaminsky, "Conceptual approaches to the measurement of financial risks", Finance of Ukraine, vol. 5. pp. 78-85, 2006.

[9] EU Council (15 March 1993) Council Directive 93/6/EEC on the capital adequacy of investments firms and credit institutions [Online]. Available: https://ips.ligazakon.net/ document/view/MU93403?an=12. Accessed on: July 14, 2019.

[10] The National Bank of Ukraine (30 July 2016). Regulation №351 on approval of the Regulation on the Ukrainian banks determination of the credit risk magnitude for active banking transactions. [Online]. Available: https://zakon2.rada.gov.ua/laws/show/ v0351500-16 Accessed on: July 14, 2019. 